Anim. Behav., 1995, 50, 1031-1039

\title{
Courtship sounds and behaviour of the two saguaro-breeding Drosophila and their relatives
}

\author{
HENAR ALONSO-PIMENTEL*, HAYWARD G. SPANGLER† \& \\ WILLIAM B. HEED* \\ *Department of Ecology and Evolutionary Biology, BSW 310 and Center for Insect Science, \\ University of Arizona \\ $\dagger$ U.S. Department of Agriculture, Agricultural Research Service, Carl Hayden Bee Research Center, \\ Tucson
}

(Received 10 September 1994; initial acceptance 24 October 1994; final acceptance 6 February 1995; MS. number: A7102)

\begin{abstract}
The two saguaro-breeding Drosophila, D. nigrospiracula and $\not$. mettleri, share striking morphological similarities even though they are not closely related. Drosophila mettleri is a member of the eremophila species complex, whereas $D$. nigrospiracula is a member of the anceps species complex. Both the courtship songs and courtship behaviour of the six species in these two complexes were examined. The objectives were (1) to investigate whether courtship behaviour follows the same evolutionary trend as the morphological traits and (2) to provide further insight about the evolution of courtship behaviour in these species. Results showed that the courtship song is a phylogenetically conservative trait within both species complexes. The pattern observed in the song parameters measured can be interpreted in terms of the degree with which hybrids can be formed in the laboratory and the extent to which sympatry occurs in the geographical distribution of the species within each species complex. Compared to many other species of Drosophila in the repleta group, those of the eremophila complex possess unique features, whereas those in the anceps complex have song characters that are commonly found throughout the species group.

(C) 1995 The Association for the Study of Animal Behaviour
\end{abstract}

Most species of the genus Drosophila engage in elaborate courtships. Although some courtship elements are widespread within the genus, significant qualitative and quantitative differences exist among the species (Spieth 1952; Ewing 1983). The male wing display is the most conspicuous element of the courtship in most of the species. The wing display produces species-specific sounds that stimulate females (Waldron 1964; Bennet-Clark \& Ewing 1967, 1969; Ewing \& Bennet-Clark 1968; Ewing 1983). This specificity suggests that examining courtship behaviour of Drosophila species in a phylogenetic context can provide insight into the evolution of behavioural traits.

The two species of focus in this study are $D$. nigrospiracula and $D$. mettleri, members of the

Correspondence: H. Alonso-Pimentel, Department of Ecology and Evolutionary Biology, BSW 310 and Center for Insect Science, University of Arizona, Tucson, AZ 85721, U.S.A. H. G. Spangler is at the U.S. Department of Agriculture, Agricultural Research Service, Carl Hayden Bee Research Center, 2000 East Allen Road, Tucson, AZ 85719, U.S.A. cactophilic repleta species group, which are endemic to the Sonoran Desert of the southwestern U.S.A. and northwest Mexico. They are of special interest because they use the necrotic tissues of the same host plants (columnar cacti) for feeding and mating. In Arizona and Sonora, the host cactus is the saguaro, Carnegiea gigantea. Drosophila nigrospiracula and D. mettleri are also of particular interest because, morphologically, the adults are almost identical, although chromosome inversion data show that they cannot be very closely related (Wasserman 1982). Drosophila mettleri belongs to the eremophila complex, with $D$. micromettleri in the West Indies and D. eremophila in central Mexico (Heed 1989). These three species have similar morphology and reproductive behaviour (Heed 1989). Drosophila nigrospiracula belongs in the anceps complex with $D$. anceps and D. leonis, two other species in central Mexico. Drosophila nigrospiracula, however, shows marked morphological differences from its two relatives. The striking adult phenotypic similarities between $D$. mettleri and $D$. nigrospiracula 
have been explained as a case of morphological convergence due to the use of the same host plants (Heed \& Mangan 1986). This concept has been reinforced by a recent study of the wings of all six species; morphometric techniques have shown that, independent of size, the shapes of the wings of $D$. mettleri and $D$. nigrospiracula are more similar to each other than to any of their respective relatives (unpublished data).

In this study we present a quantitative analysis of the variation in courtship song along with a description of the courtship behaviour of the species in the eremophila and anceps complexes. The main objective is to examine whether the courtship behaviour follows a pattern parallel with the morphological variation; we predicted that $D$. nigrospiracula will be similar to the species in the eremophila complex, and $D$. anceps and $D$. leonis will differ from the rest of the species. Another aim of this investigation was to determine whether analysis of behavioural characters can provide insight about the evolution of courtship behaviour in these two Drosophila complexes.

\section{METHODS AND MATERIALS}

\section{Animals}

The flies used in this study came from the following stocks: D. mettleri (A855) from Cerro Colorado, $24 \mathrm{~km}$ northeast of Puerto de la Libertad, Sonora, Mexico; D. micromettleri (ORV 24) from Port Handerson, Jamaica, West Indies; D. eremophila $(E 13,2)$ from near Guajalejo, Taumalipas, Mexico; D. nigrospiracula (A855) (same locality as D. mettleri); D. anceps $(800.25)$ from Zumpango, Guerrero, Mexico and D. leonis (804.4) from Barranco del Rio Santiago, Guadalajara, Jalisco, Mexico.

All of our laboratory strains were reared in 8-dram shell vials containing standard food (yeast, agar, banana, malt, syrup). Drosophila nigrospiracula requires double the proportion of yeast in the food. Virgin males and females of $D$. eremophila and $D$. micromettleri were immobilized and separated on ice within $8 \mathrm{~h}$ after eclosion. For the other four species, virgin males and females were collected within $24 \mathrm{~h}$ after eclosion. About 20 flies/vial were stored at room temperature until used in the experiment (6-10 days post-eclosion for the species in the eremophila complex and 10-14 days for the species in the anceps complex).

\section{Mating Behaviour}

To view and describe the courtship behaviour, we introduced pairs of flies in polyethylene spot plates $(21 \mathrm{~mm}$ in diameter at the top, and $6 \mathrm{~mm}$ deep; Wards 18-2009*) covered at the top with a ylass cover slip $(25 \times 25 \mathrm{~mm})$. Each pair was videotaped using an NEC NC-15 CCD colour video-camera equipped with a $50-\mathrm{mm}$ automacro Olympus lens to fill most of the frame with the chamber. The camera was connected to a Panasonic VCR (NV-8950) and a Panasonic colour video monitor (CT-1331Y). At least five pairs of each species were recorded using this system. The video-recordings obtained during the recordings of the sounds (see section below) also provided information to describe the courtship behaviour.

\section{Sound Recording}

We recorded sound produced by the courting males using the following microphone and recording system. Courtship sounds were detected with pressure transducers at very close range. The recording chamber was constructed using a polyethylene spot plate, as described in the previous section. To accommodate the microphone we made a 9.4-mm-diameter hole in the centre of the bottom and glued a small plastic tube to it. Next we inserted a 9.4-mm omnidirectional electret condenser microphone (Radio Shack 270-092*) into the plastic tube so that it was level with the bottom of the spot plate. We gently transferred pairs of flies into the chamber with a small mouth aspirator and retained them there by placing a cover slip over the chamber. Some of the males of $D$. anceps did not readily sing to the female. In such cases we added another male to the chamber. We analysed only the song from one male in each case.

During sound recordings we captured fly activity within the recording chamber using a monochromatic Panasonic WV-155 video-camera equipped with a $25-\mathrm{mm}$ lens and extension tubes to fill most of the frame with the chamber. We recorded video and audio signals using a JVC BR-6200U VHS recorder. The microphone output was amplified using a Realistic 42-2101

\footnotetext{
*Mention of a proprietary product or company does not imply endorsement by the U.S. Department of Agriculture.
} 
preamplifier which was connected to the line inputs of the recorder.

For analysis we used both a Kay Elemetrics DSP Sona-Graph (Model 5500) and a video monitor. The audio signal from the video-recorder was fed to one AUX input of the Sona-Graph. For detailed analysis of temporal data, we configured the Sona-Graph to provide oscillographic analysis.

We recorded at least five pairs of each species. The sample size was limited by the infrequent courtship behaviour shown by $D$. anceps and D. leonis. In most cases we recorded all the courtships until copulation. If copulation did not occur, we stopped recording the pair after $20 \mathrm{~min}$. We recorded all data in the morning between 0900 and 1200 hours. The temperature in the recording room was $24 \pm 1^{\circ} \mathrm{C}$.

\section{Analysis of Sound Recordings}

Obtaining the same number of parameters from each song required persistence, because some courtships were brief and contained abbreviated song. We consider burst of sound to be a repetition of pulses which can be mono- or polycyclic as defined by Ewing (1979). The burst length was measured from start to finish of the burst of sound. The inter-pulse interval (IPI) was measured from the beginning of one pulse to the beginning of the next for both mono- or polycyclic pulses (Ewing 1979). In most cases we measured 20 IPIs for each pair in all six species. Other parameters of the song could not be recorded in all six species because the pattern of the song was very different between the species in the eremophila complex and the species in the anceps complex. The three species in the eremophila complex have songs with polycyclic pulses, whereas the species in the anceps complex produce bursts of monocycle pulses. The three species in the anceps complex produce songs with several bursts of sound. Thus the burst length seemed like an appropriate parameter to describe the variation in the song pattern among the three species in the anceps complex. The distance between the burst of sound (inter-burst interval, IBI) was too variable to be informative, and we could not distinguish between the longest IBI and a gap in courtship. It was also not clear how to distinguish the longest IPI versus an IBI (Crossley 1989). Usually this problem is solved by determining the longest IPIs, with longer intervals classified as IBIs. There was no ambiguity, however, with regard to the anceps complex species because the distribution of IPIs and IBIs were quite different. By contrast, the song of the species in the eremophila complex frequently consisted of just one or two isolated long bursts of sound. Therefore, we did not measure burst lengths in these species because it did not seem to be a very meaningful parameter.

The range and $50 \%$ median values of the IPI and the burst length of each individual in each species was obtained using the process (PROC) UNIVARIATE in SAS. We used non-parametric tests because of the sample size and the lack of normality evident in the distribution of these parameters. We compared the IPIs using the Kruskal-Wallis test between all six species and within each complex (PROC NPAR1WAY in SAS). Non-parametric multiple comparisons (Tukey-type test) were run pair-wise between each of the three species in each complex to determine which species were significantly different (Zar 1984). We compared the burst lengths of the species in the anceps complex using the same tests.

\section{RESULTS}

\section{Courtship Behaviour}

\section{Eremophila complex}

The courtship behaviour of the three males in the eremophila complex was qualitatively very similar. Courtship began right after the first or second physical contact between a male and a female. A male first tapped a female, then immediately started to follow that female. Usually a male followed behind or on one side of the female, sometimes changing sides. The position of males during courtship depended on the movement of both sexes. As a female moved, a male extended one wing about $70-80^{\circ}$, usually the wing closer to the female head, and vibrated it at the point of maximum displacement. The bouts of vibrations were very short if the male followed far behind the male. When a male was closer to one side of a female or when a female stood still, however, the male held the wing extended for longer periods and produced long trains of sound. Occasionally males licked the female genitalia. Between the trains of sound the wing was returned to the 
resting position. If a female gave a prompt positive response by spreading her wings, the courtship song was very brief with few scattered pulses.

Males of these species, especially $D$. mettleri, are very aggressive, and they will try to mount females without a positive response from the females. In the laboratory we have occasionally observed what appears to be a forced copulation between $D$. mettleri couples. Furthermore, postmating courtship is frequent in these three species. The most common rejection response in virgin females is to decamp from the male overtures. Mated females also decamp and constantly extrude the ovipositor. Besides the observation that $D$. mettleri males appear to be more aggressive, we did not detect other qualitative differences in the behaviour of the three species in the eremophila complex.

\section{Anceps complex}

There appeared to be more variation in mating behaviour between the species in the anceps complex. Drosophila nigrospiracula males started courting after some physical contact with the females. First they performed wing displays in any orientation to the females. The wing displays continued while they moved behind the females. This wing display of $D$. nigrospiracula males can be described as wing flicking: fast opening-closing $\left(15-20^{\circ}\right)$ movements of one and occasionally both wings. The wing displays were repeated and were accompanied by short bursts of sound. Licking the female genitalia was also observed when the females stopped moving around the chamber. Although males had a persistent courtship, they were not as aggressive as $D$. mettleri and only followed females for short periods. We also observed females fluttering their wings during courtship. Females signalled acceptance response by spreading their wings, whereas unreceptive virgin females decamped from males.

Drosophila anceps has been described previously by Spieth (1952). Our observations corroborate his description. Males tapped, moved to the rear of the female and licked the female genitalia. At the same time, the males performed some wing displays. Sometimes they extended one wing about $15^{\circ}$, and held it in this position and then vibrated it very briefly. At other times they flicked one or both wings, with fast opening-closing movements similar to those of D. nigrospiracula. Males usually moved slightly to the side of the females so the body and vibrating wing became closer to the female head. Males were observed to circle around the females and face them for few seconds, then return to the rear of the females. Licking was very frequent in this species. Drosophila anceps females, in contrast to D. nigrospiracula, did not decamp very frequently. Males showed a persistent courtship if the females stood still, but they did not follow females very vigorously. Unless the females gave a positive response, males never tried to mount.

Male $D$. leonis used wing flicking less frequently than did $D$. anceps, and most of the time they vibrated their wings at $15^{\circ}$ extension. Males positioned themselves almost at $90^{\circ}$ on one side of the females and then turned the abdomen towards the female head, vibrating one wing. While vibrating, males also licked the female genitalia. Males alternated sides with respect to the females and also circled the females facing them. As in $D$. anceps, females of $D$. leonis did not decamp away from males; usually they stood still, sometimes extruding the ovipositor or making no obvious response to the males. If the females decamped, males did not follow them vigorously.

\section{Courtship Song}

\section{Eremophila complex}

The three species in the eremophila complex had the same overall structure of the song (Fig. 1a). There was an irregular pattern of few polycycle pulses, with long IPIs followed by a train of evenly spaced and shorter IPIs (Fig. 1). The first irregular pulses seemed to be attempts to initiate the vibrating display. The wing was brought to the vibrating position $\left(70-80^{\circ}\right)$ and returned immediately to its resting position. This behaviour pattern was usually associated with the decamping of the female. A highly regular patterned song was produced when the males obtained a stable position to the side of a motionless female.

The range of the IPIs overlapped between all the 15 males of the three species in the eremophila complex (Fig. 2). A comparison of all six species was statistically significant (Kruskal-Wallis test: $H=27.80, d f=5, \quad P<0.0001)$. The medians in the eremophila complex were around $24 \mathrm{~ms}$ for D. micromettleri males, $32 \mathrm{~ms}$ for $D$. eremophila 
(a)

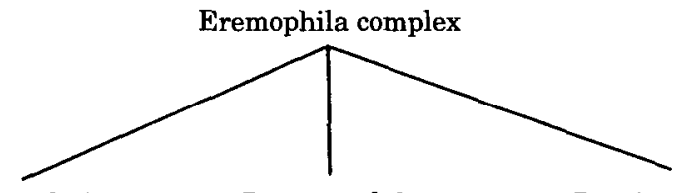

D. mettleri D. eremophila $\quad$ Dicromettleri

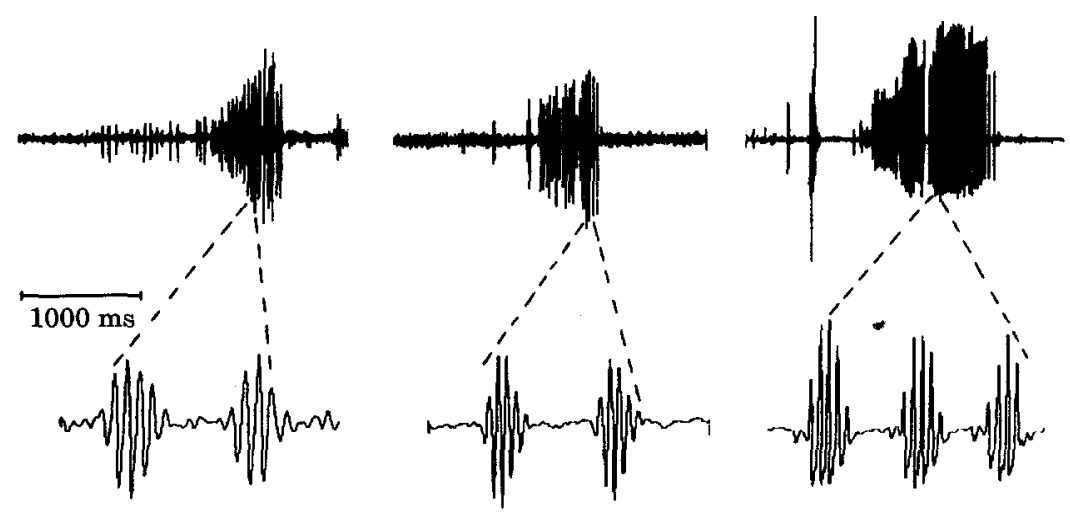

$25 \mathrm{~ms}$

(b)
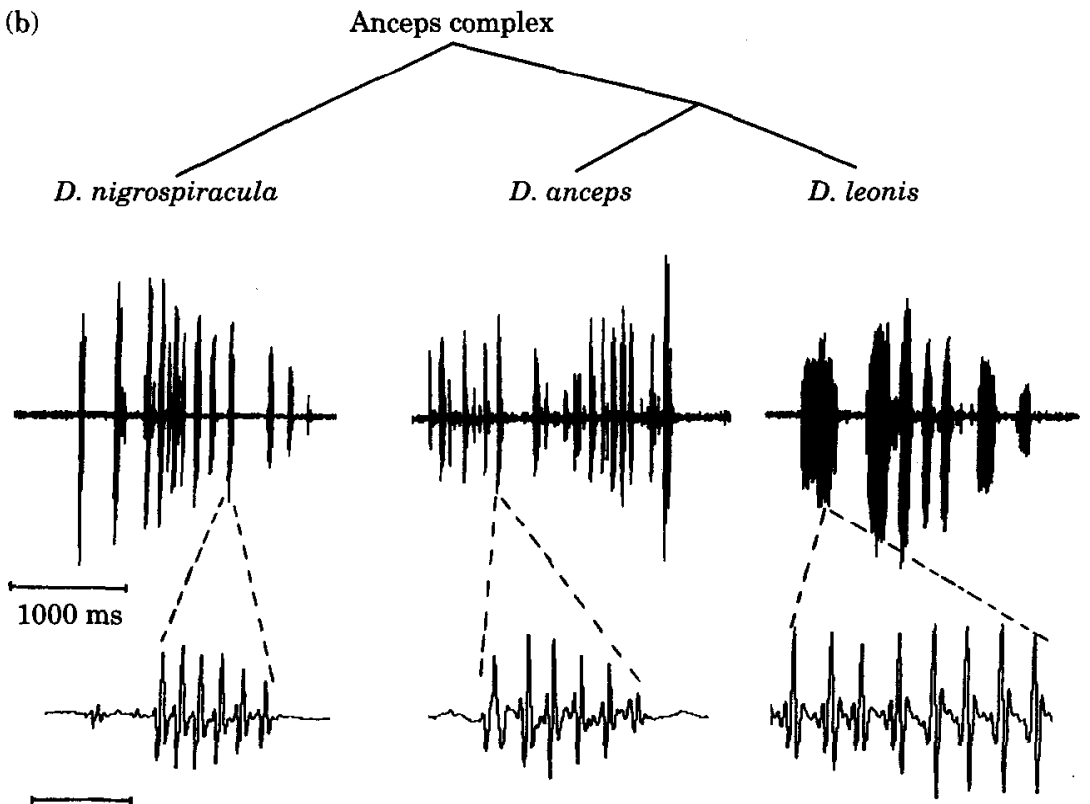

$25 \mathrm{~ms}$

Figure 1. Phylogenetic relationships of the three species in (a) the eremophila complex (from Heed 1989) and (b) the anceps complex (from Wasserman 1982), and oscillograms of each song at two different scales. 


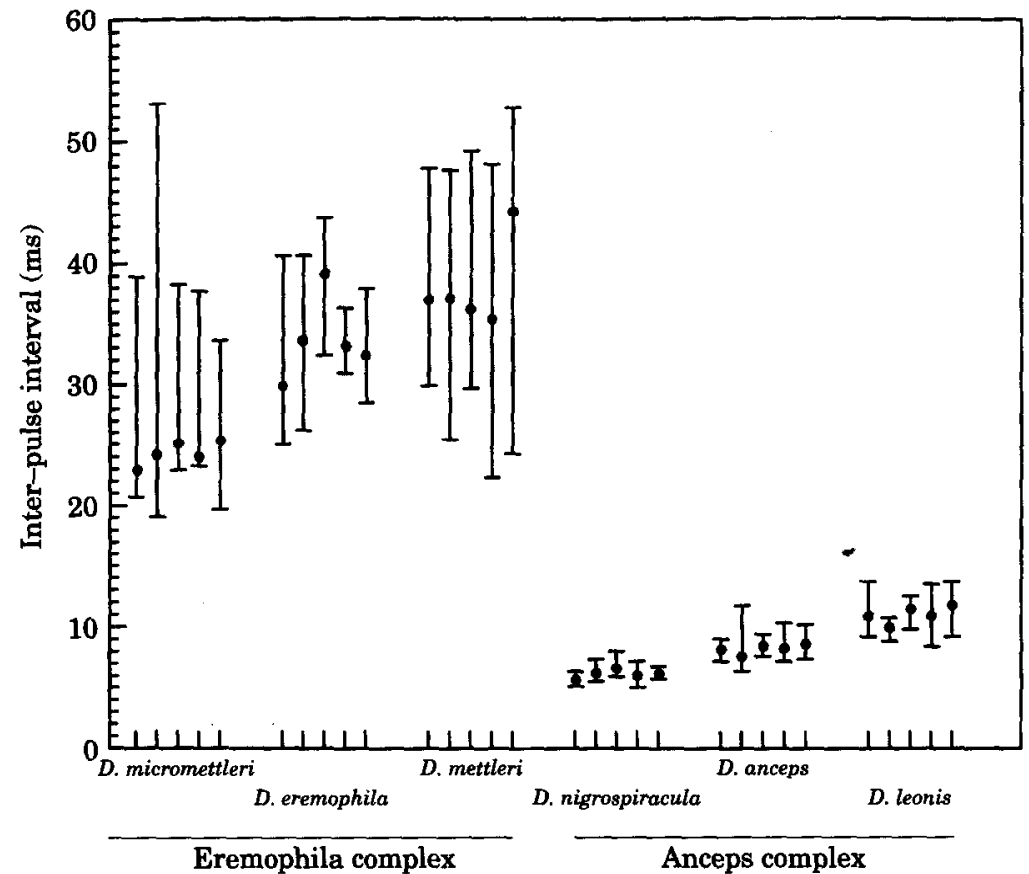

Figure 2. Range and medians of the inter-pulse interval of each individual in the three species in the eremophila complex and the three species in the anceps complex.

and $35 \mathrm{~ms}$ for D. mettleri. The three species compared together showed a significant difference (Kruskal-Wallis test: $H=10 \cdot 82, d f=2, P<0 \cdot 0045$ ). In pair-wise comparisons (non-parametric Tukeytype test), however, only the comparison $D$. micromettleri versus $D$. mettleri was significant $(P<0 \cdot 05)$.

\section{Anceps complex}

Each burst of song from the three species in the anceps complex was very similar and was characterized by monocycle pulses with very short IPIs (Fig. 1b). In this complex the Kruskal-Wallis test was also statistically significant $(H=12 \cdot 52, d f=2$, $P<0.0019$ ). In a pair-wise comparison, however, the only significant difference occurred between $D$. nigrospiracula and $D$. leonis (non-parametric Tukey-type test: $P<0 \cdot 05$ ).

The burst length in $D$. nigrospiracula and D. anceps ranged from 14 to $65 \mathrm{~ms}$; however, D. leonis males produced bursts of sound ranging from 43 to $360 \mathrm{~ms}$ (Fig. 3). Drosophila leonis differed markedly in this parameter from its two relatives (non-parametric Tukey-type test: $P<0 \cdot 05$ ). The variation of burst length was clearly associated with distinct wing display performed by the males of each species. Drosophila nigrospiracula males flicked one wing in an intermittent scissor-like manner, producing short bursts of sound. The wing was not held at the maximum displacement point and vibrated for a long period of time; thus only short bursts of sound were produced (Fig. 3). Drosophila anceps had a more complex and variable wing display. It also produced short repeated bursts of sound clearly associated with fast flicking of the wing, as did D. nigrospiracula. At other times, however, the wing was held at the maximum displacement point and vibrated. In $D$. anceps this vibration was usually performed in a slow chopped pace, which produced very short bursts of two or three pulses repeated in regular intervals. The short burst length reported for individuals 4 and 5 (Fig. 3) resulted from such a wing display. In $D$. leonis flicking was almost absent. By holding the wing at the displacement point, occasionally short repeated bursts were produced, as in D. anceps. All the D. leonis males analysed, however, produced the long trills much more frequently by vibrating the wings continuously (Fig. 3). 


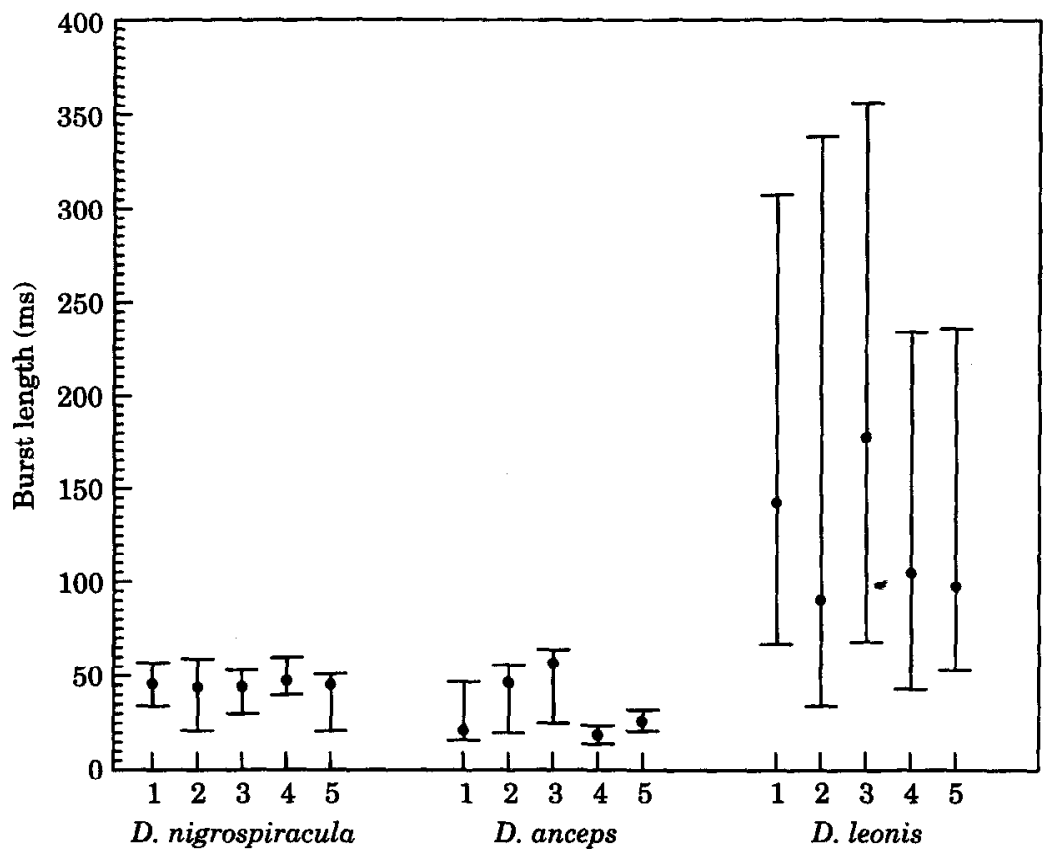

Figure 3. Range and medians of the burst length of the three species in the anceps complex.

\section{DISCUSSION}

This study shows that the courtship behaviour and the song of the species in the eremophila complex and the anceps complex follow the phylogenetic pattern of the chromosome inversion data (Fig. 1a, b). Our results indicate no evidence of convergence at the behavioural level; the trend in the evolution of morphological and behavioural traits is not parallel between these two complexes. The behavioural traits, in this case, are superior to morphological traits as indicators of phylogenetic relationships (De Queiroz \& Wimberger 1993). In other Drosophila groups, however, the courtship sounds do not reflect phylogenetic relationships (Ewing 1970; Chang \& Miller 1978).

One suggested function of the song is to maintain sexual isolation (Bennet-Clark \& Ewing 1969). Because D. mettleri and D. nigrospiracula share the same host plant, the differences in the song may be a mechanism to avoid inter-breeding. Laboratory observations, however, have shown that these two species do not court each other at all. Indirect evidence suggests that they do not recognize each other because of differences in their cuticular hydrocarbons (Markow \& Toolson
1992). Furthermore, the similarity in song between each of the saguaro breeders and their respective relatives reinforces the idea that these differences have not evolved to maintain reproductive isolation, but merely reflect phylogenetic relationships.

Each of the three species in the anceps complex has unique courtship elements. Similarly, $D$. anceps and $D$. leonis share a few characteristics, absent in $D$. nigrospiracula, such as wing vibration at $15^{\circ}$ and the female's infrequent use of the decamping response. Despite these unique features of $D$. anceps and $D$. leonis, $D$. nigrospiracula shares more similarities with its relatives than with any of the species in the eremophila complex. Because song parameters such as IPI and burst length are mainly under the control of the nervous system and are not much affected by wing morphology (Ewing 1989), the lack of correlation between wing shape convergence and the production of similar courtship songs is predictable.

The variation of patterns observed in the courtship song between these six species can be understood by looking at the characteristics within each complex rather than comparing both complexes. Closely related allopatric species share strong similarities in courtship parameters (Ewing \& 
Bennet-Clark 1968; Hoikkala et al. 1982). Strong selection for courtship and song divergence is not expected between closely related species that are geographically isolated from each other (BennetClark et al. 1980; Ewing 1989). The three species in the eremophila complex have allopatric distributions and hybridize in the laboratory (Heed 1989). Interspecific crosses imply that the females of these species still recognize the courtship patterns of their relatives. All this information is in agreement with the extreme similarity in courtship behaviour and courtship song observed in the eremophila complex.

The pattern of variation observed in the anceps complex is also consistent with the distribution of the species and data on interspecific crosses. The only hybrid crosses obtained were between $D$. nigrospiracula females and D. anceps males (Heed 1989). Although this cross is infertile, it does suggest that courtship patterns are still partially recognized between these two species. One recognition factor could be the similarities between $D$. nigrospiracula and $D$. anceps in the two IPI and burst length parameters of the song (Figs 2, 3).

Regarding species distributions, D. nigrospiracula has an allopatric distribution with respect to its relatives. Drosophila anceps and D. leonis, however, are sympatric in part of their distribution (Heed 1982). Because of the possible role of the song as a species isolating mechanism, the courtship song should differ most markedly between closely related sympatric species (Ewing 1970; Crossley 1986), although we do not have experimental data to show that the courtship song actually isolates $D$. anceps and $D$. leonis.

The songs of several species of the repleta group, including $D$. anceps, have been described by Ewing \& Miyan (1986). With respect to the parameters measured, Ewing \& Miyan (1986) reported that $D$. anceps has a median IPI of $9.6 \mathrm{~ms}$ with a range of 6-13 ms, and our study showed a median IPI of $8 \cdot 2 \mathrm{~ms}$ with a range of $6-12 \mathrm{~ms}$. These small differences between the two studies are probably due to environmental differences and/or differences in analysis of the data.

Compared to other subgroups and complexes in the repleta group, the eremophila complex is quite distinctive; it has polycyclic pulses with long IPIs (>24 ms). By contrast, the songs of the anceps complex, like most of the repleta group species, have monocycle pulses with shorter IPIs (<20 ms).
Polycyclic pulses are present only in the hydei subgroup of the repleta group. The work by Yum et al. (1991) on the Adh locus suggests that the hydei subgroup is indeed the sister group of the eremophila complex. Thus, if there is an eremophila-hydei clade, the polycyclic pulses in such a clade would be considered a conservative element of the song.

In contrast to their convergent morphologies, no evidence indicates that $D$. nigrospiracula and D. mettleri have converged in any of the courtship behaviour elements. The courtship song is clearly a phylogenetically conservative trait within the eremophila and the anceps complexes. The sparsity of interspecific crosses suggests that the anceps complex is an old lineage (Heed 1989), which might explain the variation found within this complex. On the other hand, the eremophila complex may be a more recent lineage whose species share striking similarities at the morphological and behavioural level. Compared to other repleta species, the eremophila complex possess unique features, some of which are common in species of the hydei subgroup, whereas the species in the anceps complex share similar song characteristics with many of the other repleta group flies.

\section{ACKNOWLEDGMENTS}

We thank Juan Francisco Ornelas, Thomas $\mathrm{R}$. Tobin and Kiyomi Morino for their comments on the manuscript and Eric G. Dyreson for helping with the analysis of the data. The research was supported by the DuPont Aid in Education programme to H. A.-P.

\section{REFERENCES}

Bennet-Clark, H. C. \& Ewing, A. W. 1967. Stimuli provided by courtship of male Drosophila melanogaster. Nature, Lond., 215, 669-671.

Bennet-Clark, H. C. \& Ewing, A. W. 1969. Pulse interval as a critical parameter in the courtship song of Drosophila. Anim. Behav., 17, 755-759.

Bennet-Clark, H. C., Leroy, Y. \& 'Tsacas, L. 1980. Species and sex-specific song and the courtship behaviour in the genus Zaprionus (Diptera-Drosophilidae). Anim Behav, 28, 230-255.

Chang, H. C. \& Miller, D. D. 1978. Courtship and mating sounds in species of the Drosophila affinis subgroup. Evolution, 32, 540-550.

Crossley, S. A. 1986. Courtship sounds and behaviour in the four species of the Drosophila bipectinata complex. Anim. Behav., 34, 1146-1159. 
Crossley, S. A. 1989. On Kyriacou \& Hall's defence of courtship song rhythms in Drosophila. Anim. Behav., 37, 861-863.

De Quciroz, A. \& Wimberger, P. H. 1993. The usefulness of behavior for phylogeny estimation: levels of homoplasy in behavioral and morphological characters. Evolution, 47, 46-60.

Ewing, A. W. 1970. The evolution of courtship songs in Drosophila. Revue Comportement Anim., 4, 3-8.

Ewing, A. W. 1979. Complex courtship songs in the Drosophila funebris species group: escape from an evolutionary bottleneck. Anim. Behav., 27, 343-349.

Ewing, A. W. 1983. Functional aspects of Drosophila courtship. Biol. Rev., 58, 275-292.

Ewing, A. W. 1989. Arthropod Bioacoustics: Neurobiology and Behavior. New York: Cornell University Press.

Ewing, A. W. \& Bennet-Clark, H. C. 1968. The courtship songs of Drosophila. Behaviour, 31, 288-301.

Ewing, A. W. \& Miyan, J. A. 1986. Sexual selection, sexual isolation and the evolution of song on the Drosophila repleta group of species. Anim. Behav., 34, 421-429.

Heed, W. B. 1982. The origin of Drosophila in the Sonoran Desert. In: Ecological Genetics and Evolution the Cactus-Yeast-Drosophila Model System (Ed. by J. S. F. Barker \& W. T. Starmer), pp. 65-80. New York: Academic Press.

Heed, W. B. 1989. Origin of Drosophila of the Sonoran Desert revisited: in search of a founder event and the description of a new species in the eremophila complex. In: Genetics, Speciation and the Founder Principle (Ed. by L. V. Giddings, K. Y. Kaneshiro \& W. W. Anderson), pp. 253-278. New York: Oxford Press.
Heed, W. B. \& Mangan, R. L. 1986. Community ecology of the Sonoran Desert Drosophila. In: The Genetics and Biology of Drosophila, Vol. 3e (Ed. by M. Ashburncr, H. L. Carson \& J. N. Thompson), pp. 311-345. London: Academic Press.

Hoikkala, A., Lakovaara, S. \& Romppainen, E. 1982. Mating behavior and male courtship sounds in the Drosophila virilis group. In: Advances in Genetics, Development and Evolution of Drosophila (Ed. by S. Lakovarra), pp. 407-421. New York: Plenum Press.

Markow, T. A. \& Toolson, E. C. 1992. Temperature effects on epicuticular hydrocarbons and sexual isolation in Drosophila mojavensis. In: Ecological and Evolutionary Genetics of Drosophila (Ed. by J. S. F. Barker, W. T. Starmer \& R. J. MacIntyre), pp. 315-330. New York: Plenum Press.

Spieth, H. T. 1952. Mating behavior within the genus Drosophila (Diptera). Eull. Am. Mus. nat. Hist., 99, 395-474.

Waldron, I. 1964. Courtship sound production in two sympatric sibling Drosophila species. Science, 144, 191-193.

Wasserman, M. 1982. Evolution in the repleta group. In: The Genetics and Biology of Drosophila, Vol. $3 b$ (Ed. by M. Ashburner, H. L. Carson \& J. N. Thompson), pp. 61-139. London: Academic Press.

Yum, J., Starmer, W. T. \& Sullivan, D. T. 1991. The structure of the Adh locus of Drosophila mettleri: an intermediate in the evolution of the Adh locus in the repleta group of Drosophila. Molec. Biol. Evol., 8, $857-867$.

Zar, J. H. 1984. Biostatistical Analysis. Englewood Cliffs, New Jersey: Prentice-Hall. 